\title{
Craniofacial Anthropometric Profile of Adult Bangladeshi Buddhist Chakma Females
}

\author{
Asma Mostafa, ${ }^{1}$ Laila Anjuman Banu, ${ }^{2}$ Fashiur Rahman, ${ }^{3}$ and Sudip Paul ${ }^{4}$ \\ ${ }^{1}$ Department of Anatomy, Chattagram Maa-O-Shishu Hospital Medical College, Chittagong 4100, Bangladesh \\ ${ }^{2}$ Department of Anatomy, Bangabandhu Sheikh Mujib Medical University, Dhaka 1000, Bangladesh \\ ${ }^{3}$ Department of Dermatology and Venereology, Mymensingh Medical College, Mymensingh 2200, Bangladesh \\ ${ }^{4}$ Department of Biochemistry and Molecular Biology, Jahangirnagar University, Savar, Dhaka 1342, Bangladesh \\ Correspondence should be addressed to Sudip Paul; sudippaul.bcmb@gmail.com
}

Received 21 May 2013; Revised 7 August 2013; Accepted 21 August 2013

Academic Editor: Kaushik Bose

Copyright (c) 2013 Asma Mostafa et al. This is an open access article distributed under the Creative Commons Attribution License, which permits unrestricted use, distribution, and reproduction in any medium, provided the original work is properly cited.

\begin{abstract}
The present descriptive, observational, and cross-sectional study was designed to establish the baseline measurements of the craniofacial anthropometrical parameters and indices of 100 adult Bangladeshi Buddhist Chakma females aged between 25 and 45 years, residing at different locations of Chittagong and Rangamati cities. A total of ten craniofacial variables were measured using physical and photographic procedures. Craniofacial indices were calculated from those craniofacial variables. The craniofacial indices showed that Chakma females are mostly hyperbrachycephalic, hypereuryprosopic, and mesorrhine, with intermediate eyes and long narrow ears.
\end{abstract}

\section{Introduction}

Morphological characteristics in human beings are affected by ecological, biological, geographical, racial, gender, and age factors [1]. Most studies have emphasized the importance of anthropometric study on the basis of the above factors. This necessity rests on the fact that there will be greater validity if an individual is compared to referent data matched for their specific ethnic, sex, and age group. A hallmark of the diversity and individuality of the people encountered in daily life is the range of variations in the shape of their faces. Studies on craniofacial relations and variations in man will assist in understanding the frequency distribution of human morphologies [2]. Craniofacial anthropometrics have become an important tool for genetic counselors to identify any dysmorphic syndromes [3]. Measurements taken from a patient can be compared with the normal values obtained from a reference population, and deviations from the normative values can be evaluated. Cephalometric results are also used in forensic medicine for facial reconstruction, a technique, to recreate an individual's face for the purpose of identification [4]. Cephalometric data are helpful in identifying the deceased, especially in investigations of genocide and mass death resulting from wars, accidents, terrorist attacks, and so forth. Cephalometric results are also used in plastic and reconstructive surgery, oral surgery, and dentistry to treat any congenital or post-traumatic facial disfigurements in members of different ethnic groups [5]. A normative reference value helps the clinician to precise the determination of the degree of deviations and to assess any improvement achieved through treatment.

Chakma is the largest ethnic group found in the hilly areas of Eastern Bangladesh [6]. They are Mongoloid in origin [7]. They are descendants of the ancient kingdom of Champaknagar in Northern India [8]. According to the 1991 population census of Bangladesh, their number is 2,53,000, and more than 90 percent of them are residing in Rangamati and Khagrachari districts [6]. There are also about 80,000 Chakmas in Mizoram, Arunachal, and Tripura in India and 20,000 in Myanmar [6]. Chakmas form the largest Buddhist population in Bangladesh, and they follow the Southern or the Theravada form of Buddhism [9]. Chakmas call their village "Adam". The head person of the Chakma tribe is the Chakma king. Most Chakmas speak in Chakma and 
Bengali languages [9]. The staple food of Chakma is rice, supplemented by millet, corn, vegetables, and mustard. Fish, poultry, and meat are also eaten, despite the Buddhist taboo on consuming animal flesh [9].

It is well established that a single standard of facial aesthetics is not appropriate for the application to diverse racial and ethnic groups [10]. As no published data on craniofacial anthropometrics of adult Bangladeshi Buddhist Chakma females are available at present, the present study was designed to establish the baseline measurements of the craniofacial anthropometrical parameters and indices of this population that may be necessary for future reference in these regards. The effects of environment on the development, growth, and maturation were identified through the anthropometric study [11]. Anthropometry is an important low-cost method for the assessment of the nutritional level and general health condition [12]. So, the present study may provide aid in the planning of health measures among this population.

\section{Subjects and Methods}

The study was descriptive, observational, and cross-sectional in nature and carried out in the Department of Anatomy, Bangabandhu Sheikh Mujib Medical University (BSMMU), Dhaka, between July 2009 and June 2010. The study group consisted of a convenient sample of 100 adult Bangladeshi Buddhist Chakma females aged between 25 and 45 years residing at different locations of Chittagong and Rangamati cities. Date of birth of each subject was recorded from their birth certificate, secondary school certificate, or national identity cards. Age of each subject was calculated by subtracting the date of birth from the date of data collection [13]. Buddhist Chakma females who were mixed in originwith history of marriage with Bengali people or with any other tribe within the last three generations-with history of congenital craniofacial anomaly, major craniofacial trauma, orthodontic treatment, craniofacial reconstructive surgery, and craniofacial deformities or irregular dentitions that might affect craniofacial measurements were excluded from the study.

Ten variables namely cephalic length and breadth, morphological face height, maximum facial breadth, nose height, nose width, intercanthal width, biocular width, and left ear length and width [14] were analyzed through physical and photographic procedures in the present study.

The variables cephalic index, facial index, nasal index, intercanthal index, and auricular index were calculated. The cephalic index is the ratio of cephalic breadth to the cephalic length expressed as percentage [15]. The facial index is the ratio of the morphological face height to the maximum facial breadth expressed as percentage [15]. The nasal index is the ratio of the nose width to the nose height as percentage [15]. The intercanthal index is the ratio of the intercanthal width to the biocular width as percentage [16]. The auricular index is the ratio of the ear width to the ear length as percentage [17].
The head, face, nose, eyes, and ears are then classified according to their index into different classes as discussed elsewhere [15-17].

2.1. Procedures of Measuring the Variables Studied. The physical measurements and frontal facial photographs were taken at a fixed time between $9 \mathrm{AM}$ and $5 \mathrm{PM}$ to eliminate the discrepancies due to diurnal variations [18]. All the physical measurements were taken using the digital sliding caliper or spreading caliper.

The orbital measurements were taken using the photographic procedure. This procedure had been shown to provide a valid alternative to the use of manual anthropometry $[19,20]$. Before taking the frontal facial photograph, each subject was asked to maintain a neutral, relaxed facial expression, gaze upward, without lifting head, and to breathe calmly through their nose [14]. All photographs were taken with a digital camera, at a 7.2 megapixel resolution, under the same lighting conditions using flash mode from a fixed distance of 4 feet using the zoom function [21]. Then, the measurements were taken in Adobe Illustrator Version-10.

The "nose height," measured physically, was used to convert the photograph into actual size using the transform tool of the Adobe Illustrator. After that, the pen tool was used to place landmarks on eyes, and the selection tool was used to take the reading from the transform tool.

All measurements were taken twice to control the measurement error. The final value that was used for the study was the average of the two obtained values. A third reading was taken if the initial two measurements showed a major discrepancy, and the two closer readings would then be used [22].

2.2. Data Processing and Analysis. After the collection of the data, their frequency distributions, central tendencies, and dispersions were determined, and results were prepared in terms of frequency distributions, ranges, means, and standard deviations (SD) using SPSS version 12.0.

\section{Results}

The ranges, mean values, and standard deviations of craniofacial variables and indices are listed in Tables 1 and 2. The 50th, 75th, 85th, and 95th percentile values of the craniofacial measurements and indices are given in Table 3.

In case of cephalic index, it was found that about $80 \%$ of the Chakma females were hyperbrachycephalic (Figure 1(a)). The next most common type (16\%) was brachycephalic. No dolichocephalic female was found (Figure 1(a)). Figure 1(b) shows that $58 \%$ of the cephalic indices ranged between 85 and 90. In $1 \%$ case, the cephalic index was more than 100 , indicating a larger cephalic breadth than cephalic length (Figure 1(b)). Figure 1(b) also shows that data are following a normal distribution curve.

Most of the Chakma females (68\%) examined in the present study have hypereuryprosopic or very broad face (Figure 2(a)). The next most common type (25\%) was 
TABLE 1: Measurements of craniofacial variables obtained through physical or photographic procedure.

\begin{tabular}{lcc}
\hline \multirow{2}{*}{ Variable } & \multicolumn{2}{c}{ Measurement } \\
& Mean $(\mathrm{cm}) \pm$ SD & Range $(\mathrm{cm})$ \\
\hline Cephalic length & $16.88 \pm 0.57$ & $14.70-18.30$ \\
Cephalic breadth & $14.89 \pm 0.62$ & $11.30-16.68$ \\
Morphological face height & $10.59 \pm 0.48$ & $9.10-11.80$ \\
Maximum facial breadth & $13.74 \pm 0.60$ & $12.18-14.90$ \\
Nose height & $4.32 \pm 0.30$ & $3.70-5.19$ \\
Nose width & $3.48 \pm 0.26$ & $2.88-4.12$ \\
Intercanthal width & $3.12 \pm 0.26$ & $2.48-3.61$ \\
Biocular width & $7.91 \pm 0.47$ & $6.81-9.00$ \\
Left ear length & $5.78 \pm 0.36$ & $4.76-6.92$ \\
Left ear width & $3.01 \pm 0.23$ & $2.47-3.88$ \\
\hline
\end{tabular}

$N=100$ for each variable.

TABLE 2: Measurements of calculated craniofacial indices.

\begin{tabular}{lcc}
\hline Craniofacial index & \multicolumn{2}{c}{ Measurement } \\
& Mean \pm SD & Range \\
\hline Cephalic index & $88.31 \pm 4.46$ & $67.66-101.37$ \\
Facial index & $77.22 \pm 4.54$ & $68.38-90.09$ \\
Nasal index & $80.78 \pm 7.46$ & $66.98-105.38$ \\
Intercanthal index & $39.42 \pm 2.09$ & $33.34-43.79$ \\
Auricular index & $52.20 \pm 4.10$ & $43.17-64.47$ \\
\hline
\end{tabular}

$N=100$ for each index.

TABle 3: Percentile values for craniofacial measurements and indices.

\begin{tabular}{lcccc}
\hline \multirow{2}{*}{ Variable } & \multicolumn{4}{c}{ Percentile value } \\
& 50 & 75 & 85 & 95 \\
\hline Cephalic length & 16.90 & 17.19 & 17.30 & 17.80 \\
Cephalic breadth & 14.88 & 15.18 & 15.40 & 15.90 \\
Morphological face height & 10.58 & 10.95 & 11.04 & 11.36 \\
Maximum facial breadth & 13.80 & 14.18 & 14.50 & 14.70 \\
Nose height & 4.31 & 4.52 & 4.65 & 4.82 \\
Nose width & 3.48 & 3.63 & 3.77 & 3.90 \\
Intercanthal width & 3.13 & 3.33 & 3.41 & 3.57 \\
Biocular width & 7.89 & 8.25 & 8.41 & 8.72 \\
Left ear length & 5.79 & 5.99 & 6.11 & 6.40 \\
Left ear width & 2.99 & 3.10 & 3.21 & 3.41 \\
Cephalic index & 88.10 & 90.70 & 92.78 & 96.10 \\
Facial index & 77.01 & 79.93 & 81.44 & 85.30 \\
Nasal index & 79.93 & 85.43 & 88.68 & 94.99 \\
Intercanthal index & 39.36 & 40.67 & 41.61 & 43.05 \\
Auricular index & 52.19 & 54.48 & 56.56 & 58.95 \\
\hline
\end{tabular}

euryprosopic. No hyperleptoprosopic female was found (Figure 2(a)). Figure 2(b) shows that most (45\%) of the facial indices ranged from 75 to 80 . In another $19 \%$ of the cases, the facial index ranged from 80 to 85 . Figure 2(b) also shows that data are following a normal distribution curve.

In case of nasal index, most of the Chakma females (69\%) have a mesorrhine or a medium nose (Figure 3(a)). The next most common type (23\%) is platyrrhine or broad nose. No hyperleptorrhine or very narrow nose was found (Figure 3(a)). Figure 3(b) shows that $28 \%$ of the nasal indices ranged from 75 to 80 , and $24 \%$ of the nasal indices ranged from 80 to 85 . In $3 \%$ of the cases, nasal index was more than 100 indicating a larger nose width than nose height. The distribution of data is positively skewed (Figure 3(b)).

Most of the Chakma females (88\%) have an intermediate eye (Figure $4(\mathrm{a})$ ). The next most common type (12\%) is close eye. No far apart eye was found (Figure 4(a)). Figure 4(b) shows that most $(51 \%)$ of the intercanthal indices ranged between 37 and 40 , and $37 \%$ of the intercanthal indices ranged between 40 and 44. Figure 4(b) also shows that data are following a normal distribution curve.

In case of auricular index, most of the Chakma females (97\%) have a narrow and long (large) ear (Figure 5(a)). No wide and short (small) ear was found (Figure 5(a)). Figure 5(b) shows that most (49\%) of the auricular indices ranged from 50 to 55 and in $23 \%$ cases the auricular index ranged from 45 to 50 . Figure 5(b) also shows that data are following a normal distribution curve.

\section{Discussion}

In the present study the cephalic index showed that, majority of the Chakma females were hyperbrachycephalic (very short and broad head) followed by brachycephalic (short and broad head). Similar hyperbrachycephalic head was found in Mongol [23], Evenks [24], Manchu [25], and Japanese [26] females. Lobo et al. [27] reported that Gurung females are brachycephalic. It is noted that Chakma, Gurung, Mongol, Evenks, Manchu, and Japanese are mongoloid. Therefore, these results offer support to Bhasin [28] who described Mongoloids as brachycephalic to hyperbrachycephalic. On the other hand, several authors have suggested that Asian people other than Mongoloids are also hyperbrachycephalic to brachycephalic. Anupama et al. [29] reported that Punjab females are hyperbrachycephalic. Golalipour [30] reported that Fars females are hyperbrachycephalic and Turkman females are brachycephalic. Pandey [31] reported that Onge females belong to brachycephalic head. Shah and Jadhav [18] reported that Gujarat females have brachycephalic head. Ngeow and Aljunid [22] reported a brachycephalic head shape of Indian females. Farkas et al. [5] reported that the North American White Caucasian females have a mesocephalic or medium head type. Although the Indians and Iranians are Caucasoids, the cephalic index of Indian and Iranian females show resemblance to people of Mongoloid race of Asia and differ significantly from that of the Caucasians of America. It may be the environmental influence that shows such resemblance between people of two different races of Asia. 


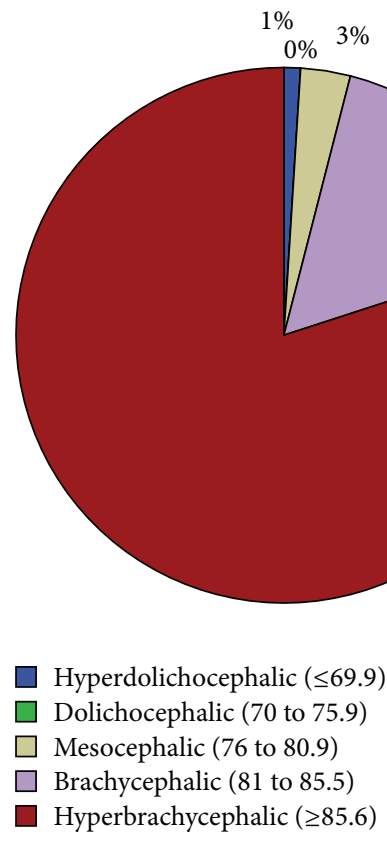

(a)

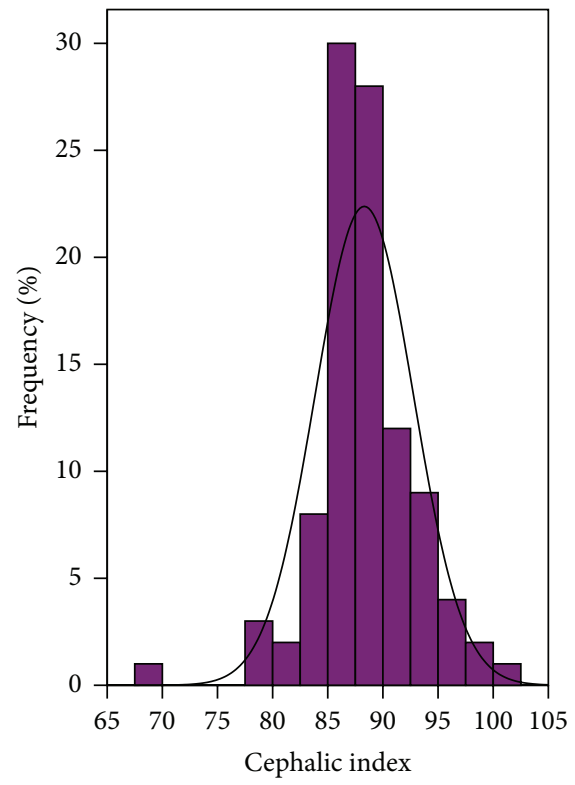

Mean $=88.31$

Std. Dev. $=4.45667$

$N=100$

(b)

FiguRE 1: (a) a pie diagram showing percentage frequencies of different shapes of head. The values within parentheses represent cephalic indices; (b) a histogram showing the frequency distribution of cephalic index with a normal curve superimposed.

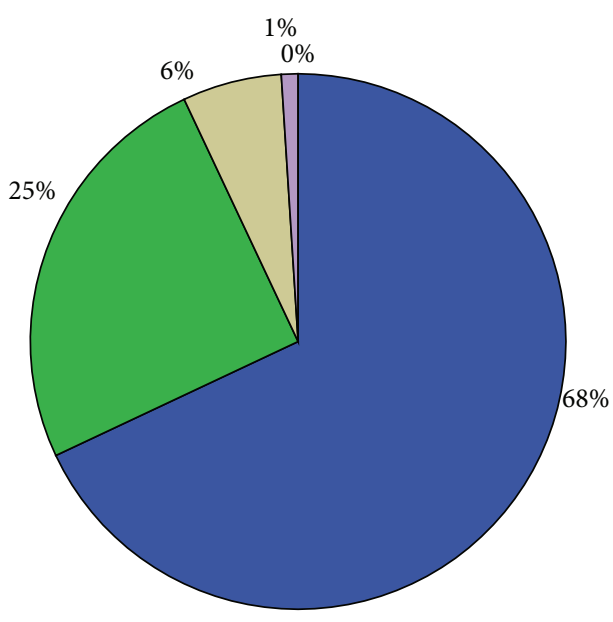

Hypereuryprosopic $(\leq 78.9)$

$\square$ Euryprosopic (79 to 83.9)

$\square$ Mesoprosopic (84 to 87.9)

$\square$ Leptoprosopic (88 to 92.9 )

$\square$ Hyperleptoprosopic $(\geq 93)$

(a)

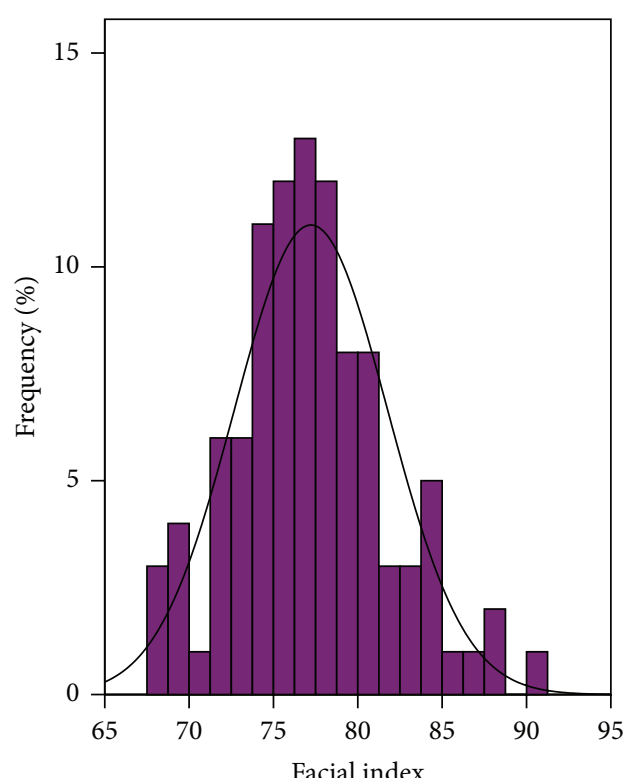

Mean $=77.2223$

Std. Dev. $=4.54221$

$N=100$

(b)

FIGURE 2: (a) a pie diagram showing percentage frequencies of different shapes of face. The values within parentheses represent facial indices; (b) a histogram showing the frequency distribution of facial index with a normal curve superimposed. 


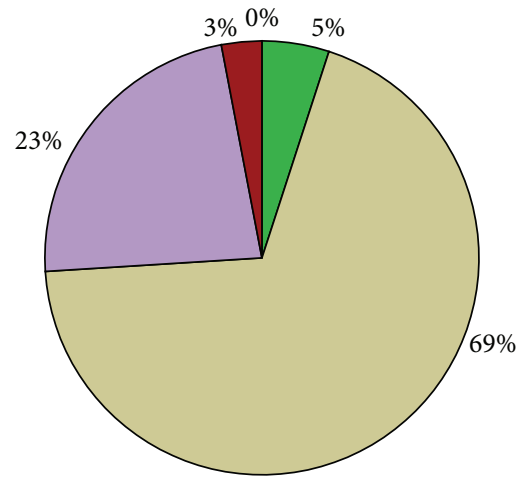

Hyperleptorrhine $(\leq 54.9)$

$\square$ Leptorrhine (55 to 69.9)

$\square$ Mesorrhine (70 to 84.9)

$\square$ Platyrrhine (85 to 99.9$)$

Hyperplatyrrhine $(\geq 100)$

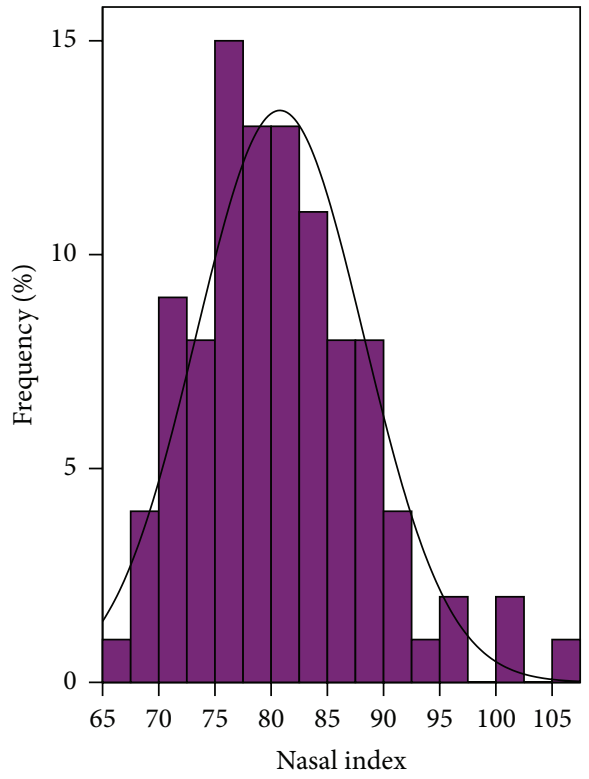

Mean $=80.7792$

Std. Dev. $=7.45889$

$N=100$

(a)

(b)

FIGURE 3: (a) a pie diagram showing percentage frequencies of different shapes of nose. The values within parentheses represent nasal indices; (b) a histogram showing the frequency distribution of nasal index with a normal curve superimposed.

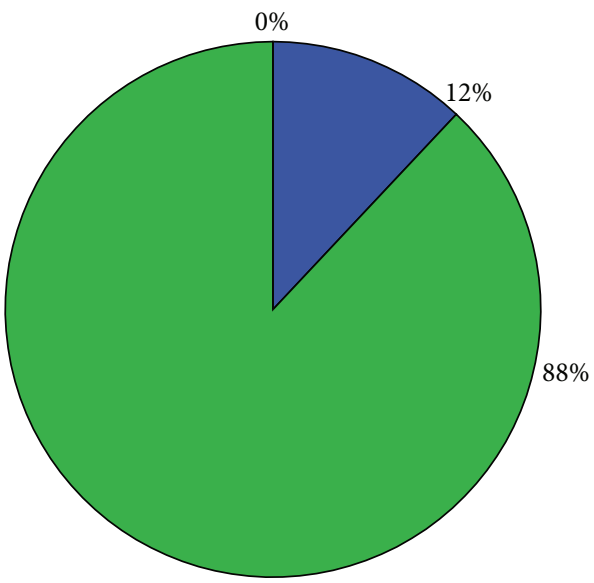

- Close $(\leq 36.9)$

$\square$ Intermediate (37 to 46)

$\square$ Far apart $(\geq 46.1)$

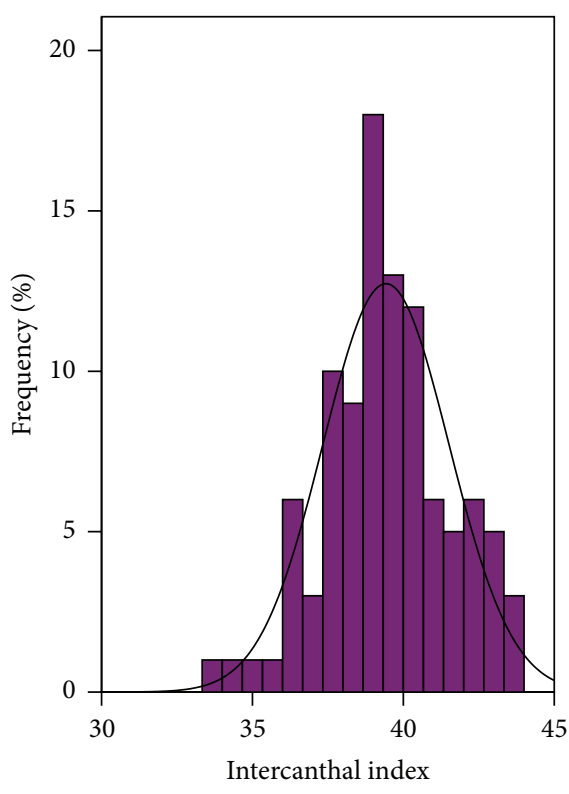

Mean $=39.4232$

Std. Dev. $=2.08914$

$N=100$

(a)

(b)

FIGURE 4: (a) a pie diagram showing percentage frequencies of different shapes of eye. The values within parentheses represent intercanthal indices; (b) a histogram showing the frequency distribution of intercanthal index with a normal curve superimposed. 


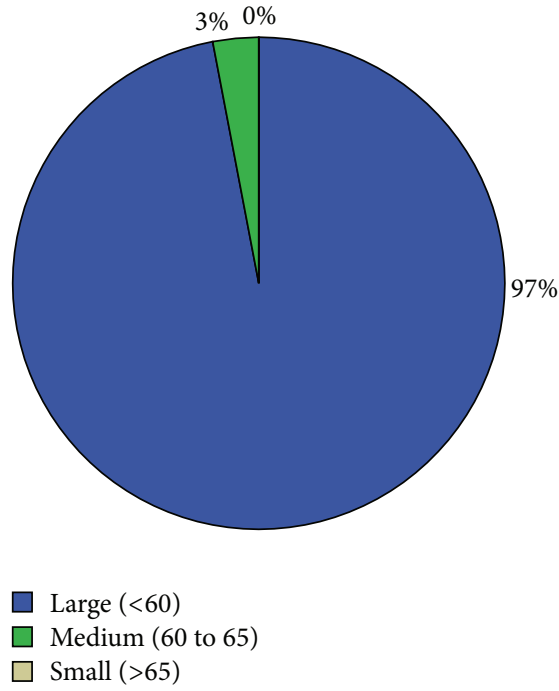

(a)

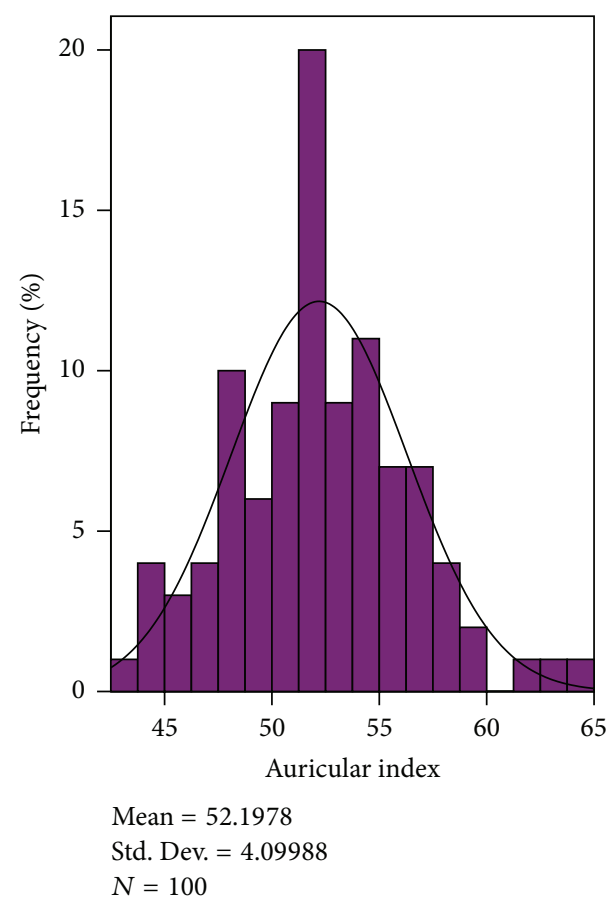

(b)

FIGURE 5: (a) a pie diagram showing percentage frequencies of different shapes of ear. The values within parentheses represent auricular indices; (b) a histogram showing the frequency distribution of auricular index with a normal curve superimposed.

In this study, the facial index showed that Chakma females were hypereuryprosopic (very broad face) followed by euryprosopic (broad face) which is in accordance with Bhasin [28] who described Mongoloids as a very broad or euryprosopic face to medium broad or mesoprosopic face. However, though Evenks [24], Mongol [23], and Manchu [25] tribes belong to Mongoloid race, they show hyperleptoprosopic or very narrow face to leptoprosopic face.

The nasal index showed that majority of the Chakma females were mesorrhine (medium nose) followed by platyrrhine (broad nose). This is in accordance with Bhasin [28] who described Mongoloids as medium or mesorrhine to broad or platyrrhine. Anthropological studies suggest that the shape of nose can be influenced by the environmental climatic condition. Large nasal index indicates broad nose which is associated with hot and moist climate, and small nasal index indicates narrow nose which is associated with cool and dry conditions [32]. As the climate of Chittagong district of Bangladesh is hot, large nasal index helps Chakmas to adapt and to survive efficiently in hot climatic conditions of their surrounding.

The mean intercanthal index in the Chakma females indicated that their eyes were intermediate. Bali et al. [33] reported that the individuals who are living at a high altitude has significantly wider intercanthal width and biocular width, thus larger intercanthal index. As the study populations of the present study live in high altitude, they show larger intercanthal index.

Thus, it may be concluded that, besides racial and ethnical factors, geographical factor can affect the form of the face.
That is why the people of different racial groups show similarities, while people of similar racial groups show variations in facial form.

\section{Conclusions}

This study showed that the adult Bangladeshi Buddhist Chakma females are mostly hyperbrachycephalic, hypereuryprosopic, and mesorrhine, with intermediate eyes and long narrow ears.

The result of this study can be useful for anatomists and anthropologists to serve as a future framework in these regards and also to compare the craniofacial dimensions of other ethnic groups of Bangladesh with this ethnic group.

\section{References}

[1] M. Jahanshahi, M. J. Golalipour, and K. Heidari, "The effect of ethnicity on facial anthropometry in Northern Iran," Singapore Medical Journal, vol. 49, no. 11, pp. 940-943, 2008.

[2] S. H. Garba, A. I. Numan, and I. G. Mishara, "Craniofacial classification of normal newborns in Maiduguri metropolis, Nigeria," International Journal of Morphology, vol. 26, no. 2, pp. 407-410, 2008.

[3] E. Nagle, U. Teibe, and D. Kapoka, "Craniofacial anthropometry in a group of healthy Latvian residents," Acta Medica Lituanica, vol. 12, no. 1, pp. 47-53, 2005.

[4] J. M. Starbuck and R. E. Ward, "The affect of tissue depth variation on craniofacial reconstructions," Forensic Science International, vol. 172, no. 2-3, pp. 130-136, 2007. 
[5] L. G. Farkas, M. J. Katic, and C. R. Forrest, "International anthropometric study of facial morphology in various ethnic groups/races," Journal of Craniofacial Surgery, vol. 16, no. 4, pp. 615-646, 2005.

[6] Bangladesh News, “The Chakma," 2008, http://www.independent-bangladesh.com/ethnic-groups/the-chakma.html.

[7] Countries and Their Cultures, "Chakmas," http://www.everyculture.com/wc/Afghanistan-to-Bosnia-Herzegovina/Chakmas.html.

[8] M. Rahman, "Chakma," Encyclopedia of World Cultures, 1996, http://www.encyclopedia.com/doc/1G2-3458000472.html.

[9] "Chakmas," http://www.banglapedia.org/HT/C_0090.HTM.

[10] O. Joy, E. Ahmed, O. Gabriel, and E. Ezon-ebidor, "Anthropometric study of the facial and Nasal length of adult Igbo ethnic group in Nigeria," Internet Journal of Biological Anthropology, vol. 2, no. 2, 2009.

[11] M. A. Sampei, N. F. Novo, Y. Juliano, F. A. B. Colugnati, and D. M. Sigulem, "Anthropometry and body composition in ethnic Japanese and Caucasian adolescent girls: considerations on ethnicity and menarche," International Journal of Obesity, vol. 27, no. 9, pp. 1114-1120, 2003.

[12] V. F. Ferrario, C. Dellavia, G. M. Tartaglia, M. Turci, and C. Sforza, "Soft tissue facial morphology in obese adolescents: a three-dimensional noninvasive assessment," Angle Orthodontist, vol. 74, no. 1, pp. 37-42, 2004.

[13] S. Ghosh and S. L. Malik, "Sex differences in body size and shape among Santhals of West Bengal," Anthropologist, vol. 9, no. 2, pp. 143-149, 2007.

[14] J. C. Kolar and E. M. Salter, Craniofacial Anthropometry: Practical Measurement of the Head and Face For Clinical, Surgical and Research Use, Charles C. Thomas, Springfield, Ill, USA, 1997.

[15] R. N. Sharma and R. K. Sharma, Anthropology, Atlantic Publishers \& Distributors, New Delhi, India, 1997.

[16] M. M. Roelofse, M. Steyn, and P. J. Becker, "Photo identification: facial metrical and morphological features in South African males," Forensic Science International, vol. 177, no. 2-3, pp. 168175,2008

[17] L. Meijerman, "Inter and intra individual variation in earprints," Leiden University Medical Center, 2006, https://openaccess .leidenuniv.nl/bitstream/1887/4292/33/Front.PDF.

[18] G. V. Shah and H. R. Jadhav, "The study of cephalic index in students of Gujarat," Journal of the Anatomical Society of India, vol. 53, no. 1, pp. 25-26, 2004.

[19] R. Edler, P. Agarwal, D. Wertheim, and D. Greenhill, "The use of anthropometric proportion indices in the measurement of facial attractiveness," European Journal of Orthodontics, vol. 28, no. 3, pp. 274-281, 2006.

[20] R. Edler, M. Abd Rahim, D. Wertheim, and D. Greenhill, "The use of facial anthropometrics in aesthetic assessment," Cleft Palate-Craniofacial Journal, vol. 47, no. 1, pp. 48-57, 2010.

[21] L. W. Simmons, G. Rhodes, M. Peters, and N. Koehler, "Are human preferences for facial symmetry focused on signals of developmental instability?" Behavioral Ecology, vol. 15, no. 5, pp. 864-871, 2004.

[22] W. C. Ngeow and S. T. Aljunid, "Craniofacial anthropometric norms of Malaysian Indians," Indian Journal of Dental Research, vol. 20, no. 3, pp. 313-319, 2009.

[23] T. Okumura, "Physical anthropological study on the measurement of head and face, and morphology of dental arch of the Mongol tribe, China," Journal of the Kyushu Dental Society, vol. 53, no. 1, pp. 01-12, 1999.
[24] S. Watanabe, "Physical anthropological study on the measurement of head and face, and morphology of dental arch on Evenks tribe, China," Journal of the Kyushu Dental Society, vol. 54 , no. 5, pp. 469-482, 2000.

[25] H. Kubo, "A study on anthropometric measurement of head and face, andmorphology of dental arch on Manchu tribe," The Journal of the Kyushu Dental Society, vol. 51, pp. 324-334, 1997.

[26] M. G. Hossain, M. Sabiruzzaman, S. Islam, F. Ohtsuki, and P. E. Lestrel, "Effect of craniofacial measures on the cephalic index of Japanese adult female students," Anthropological Science, vol. 118, no. 2, pp. 117-121, 2010.

[27] S. W. Lobo, T. S. Chandrashekhar, and S. Kumar, "Cephalic index of Gurung community of Nepal-an anthropometric study," Kathmandu University Medical Journal, vol. 3, no. 11, pp. 263-265, 2005.

[28] M. K. Bhasin, "Indian anthropology racial, ethnic, religious and linguistic elements in Indian population," 2007, http://nsdl .niscair.res.in/bitstream/123456789/339/1/pdf+4.4+NISCAIRRacial-Ethnic-Relgious-Linguistic-Groups-India-Text-Revised .pdf.

[29] M. Anupama, K. B. Singh, Seema, and B. A. P. Singh, "The study of cephalic index in Punjabi students," Journal of Punjab Academy of Forensic Medicine \& Toxicology, vol. 9, no. 2, pp. 6670, 2009.

[30] M. J. Golalipour, "The effect of ethnic factor on cephalic index in 17-20 years old females of north of Iran," International Journal of Morphology, vol. 24, no. 3, pp. 319-322, 2006.

[31] A. K. Pandey, "Cephalo-facial variation among Onges," The Anthropologist, vol. 8, no. 4, pp. 245-249, 2006.

[32] G. S. Oladipo, M. A. Eroje, and H. B. Fahwehinmi, "Anthropometric comparison of nasal indices between Andoni and Okrika tribes of Rivers State, Nigeria," International Journal of Medicine and Medical Sciences, vol. 1, no. 4, pp. 135-137, 2009.

[33] J. Bali, K. P. Chaudhary, and R. Thakur, "High altitude and the Eye: a case controlled study in clinical ocular anthropometry of changes in the eye," High Altitude Medicine and Biology, vol. 6, no. 4, pp. 327-338, 2005. 

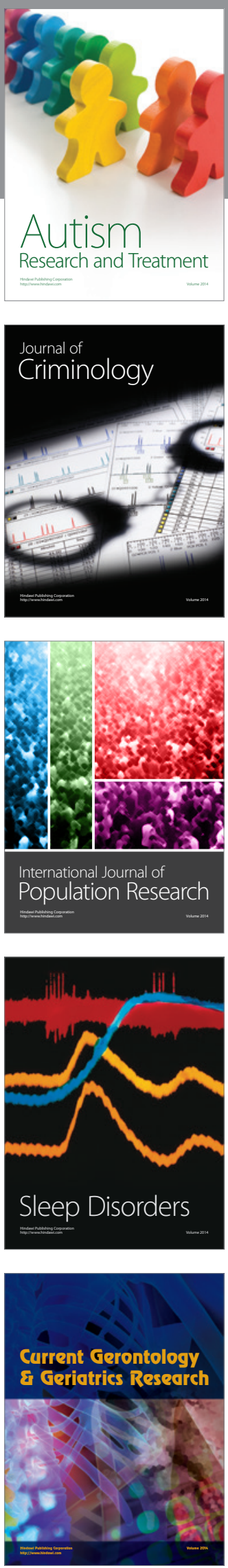
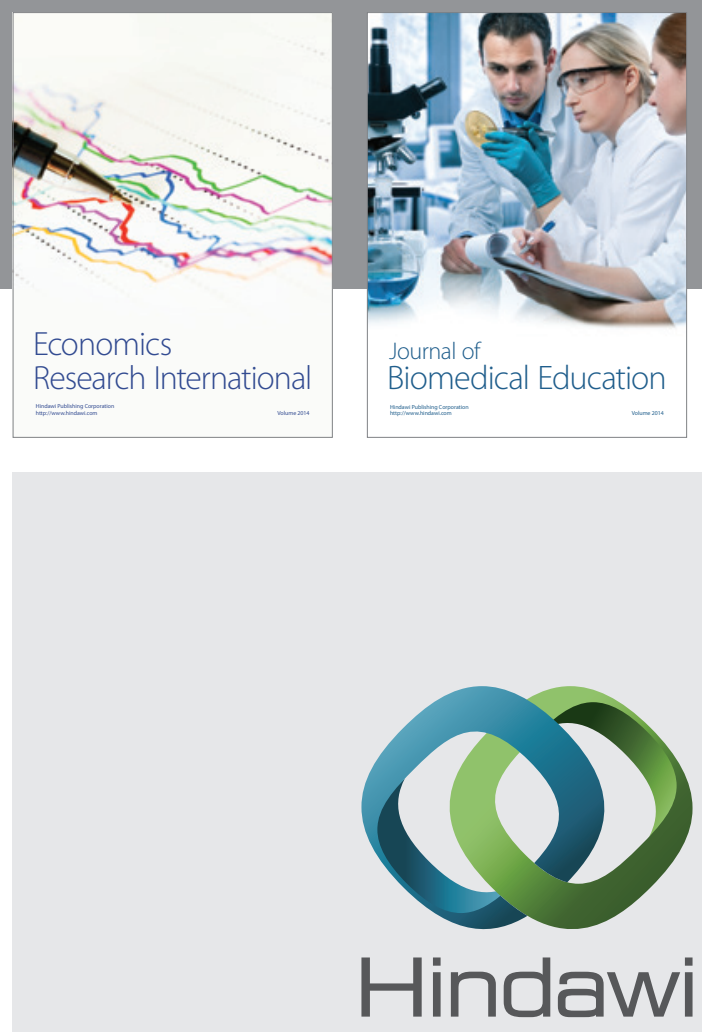

Submit your manuscripts at

http://www.hindawi.com
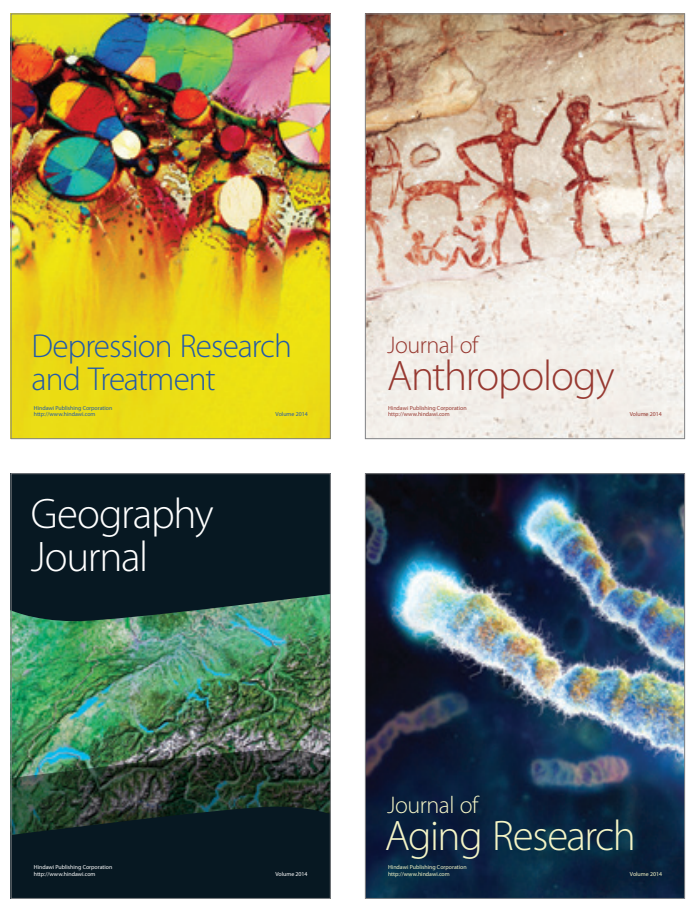
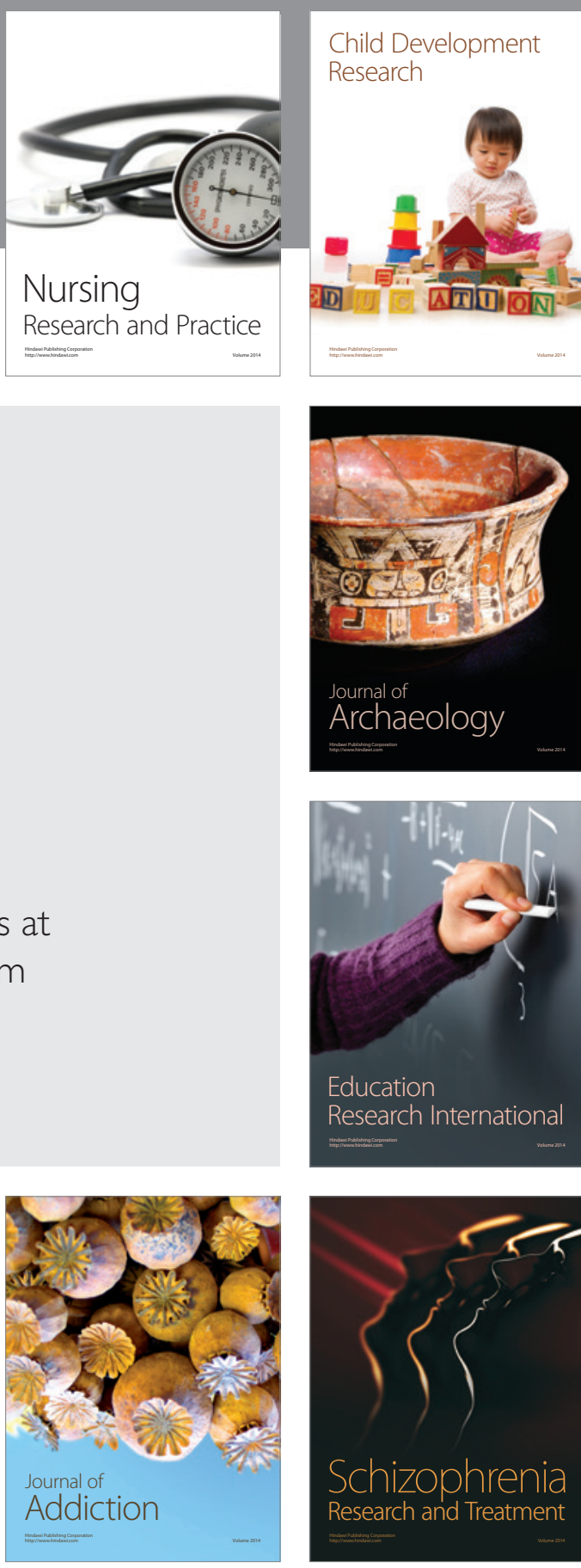

(D)
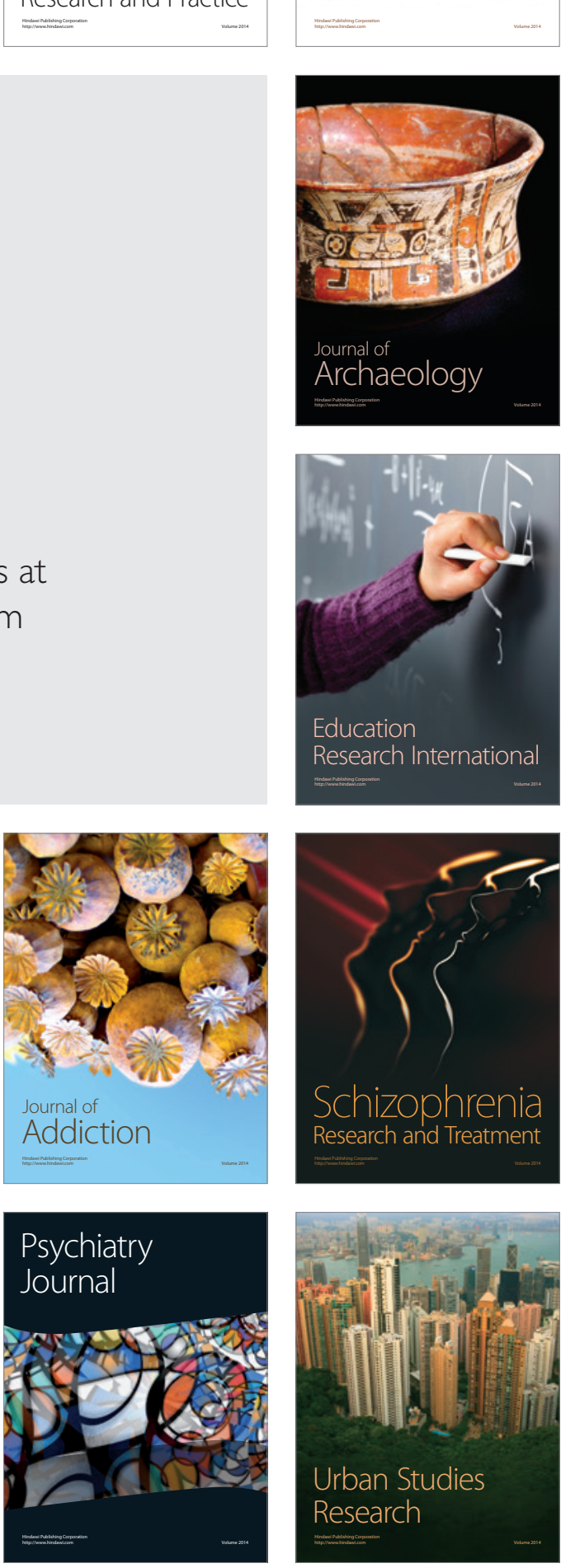